\section{EL CONTROL GUBERNAMENTAL}

\author{
Dr. JULIO V. FLORES KONJA
}

\section{I.- ORGANIZACIÓN DEL CONTROL GUBERNAMENTAL}

\section{Antecedentes}

El control gubernamental se establece a través de la organización de la administración pública peruana, determinándose tres grandes etapas:

\subsection{Organización en el instituto.- En el} siglo XV, el Imperio de los Incas o Tahuantinsuyo, era el más importante en América del Sur, por su organización, extensión territorial y adelanto cultural.

En el imperio incaico la organización se estructuró en base a lo político, económico y religioso; lo cual permitía al inca como autoridad suprema y a su consejo imperial o "Camachic", conformado por los "Apocunas" de los cuatro suyos (Antisuyo, Collasuyo, Contisuyo y Chinchaysuyo), mantener todo el control del imperio del Tahuantinsuyo desde su sede central la ciudad del Cuzco que, en lengua particular de los Incas, significa ombligo de la tierra.

En las grandes provincias participaban en el gobierno del imperio los gobernadores "Capac Apo" que eran representantes del Inca.

En orden jerárquico inmediato estaban los "Tucuyricuy" (el que todo lo ve) cuya labor era de supervisar el cumplimiento de las órdenes del Inca y su consejo imperial. El "Tucuyricuy", controlaba la labor de los funcionarios, quienes rendían cuenta de sus gestiones e informaban en forma detallada de lo expresado en los quipus, que eran un sistema de numeración y memoria por medio de cordoncillos y nudos, el que se complementaba con la "Yupana", que era una tabla de contar en hoyos en los que se colocaban las fichas (granos, piedras de colores) que permitían calcular y registrar los resultados en el quipu.

Efectuado el control por el "Tucuyricuy", se sacaba una copia del quipu para preparar el informe general anual a presentarse a las autoridades supremas del imperio en el Cuzco. Sobre esto el Inca Garcilaso dice:

"Mandaba de ley que el gobernador de la provincia tuviese un traslado de la cuenta en su poder, para que ni de parte de los indios tributarios ni de parte de los ministros cobradores hubiese alguna falsedad".

Se eligieron contadores que se llamaron "Quipucamayu", personas fieles y legales, que eran los encargados de llevar los quipus, en los que se expresaba y retenía la tradición de sus hechos y las cuentas. ya que esta fue la manera de escribir de los incas. A los "quipukamayus" acudían los curacas y los hombres nobles para conocer los acontecimientos importantes registrados por el color del hilo y por el número de nudos, lo que se complementaba conservando en la memoria los relatos contados tradicionalmente.

El inca Garcilaso de la Vega, al respecto, comenta lo siguiente:

"Yo trate los quipus y ñudos con los indios de mi padre, y con otros curacas, cuando por San Juan y Navidad venian a la ciudad a pagar sus tributos. 
Los curacas ajenos rogavan a mi madre que me mandasse les cotejasse sus cuentas, porque, como gente sospechosa. nose fiavan de los españoles que les tratassen verdad en aquel particular hasta que yo les certificara della, leyéndoles los traslados que de sus tributos me traían y cotejándolos con sus ñudos , y desta manera supe dellos tanto como los indios".

Es significativo señalar que toda su organización política y social se basaba en las normas de conducta siguientes:

No seas perezoso "Ama Kella"

No seas ladrón "Ama Sua"

No seas mentiroso "Ama Llulla"

1.2 Organización en el virreynato.- En el virreynato las autoridades eran el Virrey, la Real Audiencia. el Cabildo, el Corregidor y el Intendente.

El virrey era la máxima autoridad. quien representaba personalmente al Rey de España. Su mandato duraba cuatro o más años, a cuyo término estaba sujeto a un "juicio de residencia" ante el Consejo de Indias por los actos de su gobierno. cuyas funciones eran políticas. judiciales, militares. económicas y religiosas.

La Real Audiencia era la entidad que administraba justicia. presidida por el Virrey y por los oidores y jueces.

El Cabildo era la institución que se encargaba del gobierno de las ciudades, cuyos representantes eran los Alcaldes y Regidores, elegidos por los pobladores o designados por la autoridad.

El Corregidor era la autoridad del gobierno de una provincia denominada corregimiento. Debido a la revolución de
Túpac Amaru II en 1780) se crearon las intendencias en 1784.

Los Intendentes eran las autoridades directas en su jurisdicción. con facultades administrativas. políticas, judiciales y de control de los impuestos.

Al finalizar el siglo XVII, el virreynato tenía siete (7) intendencias (Lima. Tarma. Cuzco. Huancayo, Trujillo. Arequipa y Puno).

La organización mantenía otras dependencias con funciones específicas como las siguientes:

El Tribunal Mayor de Cuentas.

El Tribunal del Consulado.

El Resguardo.

Los Recaudadores de Impuestos.

La Casa de la Moneda.

A las disposiciones legales se denominaba "Reales Ordenes" y "Ordenanzas". las que en algunos casos se acataban pero no eran cumplidas.

\subsection{Organización en la República.- Por} la forma como ha orientado sus actividades el Estado para lograr el bienestar de la población en la República. se tiene la clasificación siguiente:

\section{a) Estado Gendarme ( 1821 - 1895 )}

En esta etapa conocida como el "dejar hacer dejar pasar". el gobierno tiene como principal actividad cuidar el orden público. debiéndose resaltar las reformas de San Martín. Bolívar y Castilla.

Después de la independencia del Perú. don José de San Martín. expide el Estatuto provisional ( 8 de octubre 1821), que crea los Ministerios de Guerra y Marina, Gobierno y Hacienda y Relaciones Exteriores. La Constitución de 1823 establece la división de los tres 
Poderes Públicos, conservando los tres ministerios y creando las prefecturas, que reemplazaron a las intendencias.

El libertador Bolívar creó en 1824, entre otros, la Contaduría General de Cuentas, dictó el decreto del 12 de Enero de 1824 contra la corrupción administrativa, que por entonces era escandalosa al dilapidarse los fondos públicos por parte de algunos funcionarios, y así establece que "todo funcionario público a quien se convenciere en juicio sumario de haber malversado o tomado para sí de los fondos públicos de diez pesos para arriba queda sujeto a la pena capital", sanción que alcanzaba también a los jueces que no cumplían con la ley.

El mariscal Castilla, en su gobierno, sobresale por el ordenamiento de la economía nacional, al elaborar el primer presupuesto del Perú con las cuentas de ingresos y egresos de los años 1845 - 1846, así como el establecimiento de las consignaciones en las ventas del guano al exterior del país. Cabe resaltar en este período la Ley general de responsabilidad de funcionarios (26 de setiembre de 1868).

\section{b). Estado Fomento ( 1895 - 1930)}

En esta etapa, el gobierno orienta el desarrollo de las actividades políticas, económicas, sociales y administrativas. El gobierno, con la creación del ministerio de "Fomento y Obras Públicas"(22 de enero de 1896), fomenta la ejecución de obras públicas en diversas lugares del país, en forma directa y con la participación de la actividad privada. En esta etapa se dictó la Ley de Contabilidad de los Ministerios ( 30 ) de octubre de 1895). Asimismo, se creó la Caja de Depósitos y Consignaciones ( $11 \mathrm{de}$ febrero de 1905).

\section{c). Estado Servicio ( 1930-1962)}

Esta etapa se orienta al bienestar de la población, tratando de proporcionar los servicios públicos esenciales que son reclamados. Así se crean los Ministerios de Educación Pública, Salud Pública y Trabajo y Previsión Social. También se crean el Banco de Fomento Agrario y el Banco Industrial.

\section{d). Estado Empresa (1962 - 1995)}

En esta etapa el gobierno orienta sus actividades tratando de reordenar los campos de la actividad pública fijando metas a cada entidad, para lo cual reestructuran la administración pública creando nuevos ministerios que se constituyen en sectores de la actividad pública; dependiendo de ellos los organismos descentralizados constituidos por las instituciones públicas encargadas de prestar servicios sin fines de lucro y las empresas del Estado encargadas de producir bienes y servicios de acuerdo el Art. 144 de la Constitución del año 1979 . La ley específica las normas de organización, funcionamiento, control y su correspondiente evaluación. Por el Art.60) de la Constitución del año 1993, el Estado reconoce el pluralismo económico, por lo que puede realizar subsidiariamente actividad empresarial, por razón de alto interés público o de manifiesta conveniencia nacional.

A la fecha se han dictado diversas normas que autorizan el proceso de privatización de las empresas, lo que está reduciendo la participación del Estado en la actividad empresarial.

\section{II.- EL SISTEMA NACIONAL DE CONTROL}

1.- Antecedentes del control de la actividad pública.- La Contraloría General de la República fue creada por 
Ley $\mathrm{N}^{\circ} 6784$ de 28 de febrero de 1930, y posteriormente normada por la Ley $\mathrm{N}^{\circ}$ 14816, Ley Orgánica del Presupuesto Funcional de la República del 6 de enero de 1964, cuyo capítulo IX trataba de las funciones y atribuciones de la Contraloría y del contralor, normatividad que concluye el 16 de noviembre de 1971 con el Decreto Ley 19039 que establece el sistema nacional de control.

La acción de control de la Contraloría se circunscribía básicamente a verificar la justificación contable y legal del gasto público. estando el juzgamiento a cargo del tribunal Mayor de Cuentas, organismo que fue asimilado por la Ley 14816.

La Contraloría General no había logrado alcanzar como organismo tutelar de los intereses del Estado el nivel que le correspondía por la falta de un sistema que integrara el proceso de las acciones de control, la carencia de planes de capacitación del personal y superposición de las funciones con otros organismos que también efectuaban el control en el sector público nacional.

Por entonces, el control se orientaba a los aspectos contables del presupuesto. dejando de lado el análisis y evaluación de los resultados de la gestión de las entidades que recaudan 0 administran rentas o bienes del Estado, como lo precisaba el artículo $10^{\circ}$ de la Constitución de la República del 9 de abril de 1933.

Al tradicional control de la legalidad y veracidad del gasto, se adiciona el control de la gestión, evaluación del control interno, así como cautelar que las entidades cumplan sus objetivos y metas, logrados con economía, eficiencia y eficacia. El control de la actividad pública, se efectúa a través del sistema nacional de control que "está constituido por los organismos, normas, métodos y procedimiento destinados al control de las entidades mixtas o asociadas y de las entidades privadas en que tengan participación el Estado o reciban fondos públicos en cuanto a la utilización de los mismos " (art. $1^{\circ}$ del Reglamento del Sistema Nacional de Control).

El D.L. 19039 Ley Orgánica del Sistema Nacional de Control (16.11.1971), se crea como una necesidad que retoma y actualiza la normatividad dictada sobre control, tal la ubicación de la Contraloría General de la República como organismo autónomo con independencia administrativa y funcional. La sistematización del ámbito de control en los campos administrativo y financiero, alcanza al personal de cualquier régimen de las entidades del Sector Público Nacional y donde el Estado participa. Requisitos para ser Contralor, son la determinación de las responsabilidades de los servidores públicos, dictar normas sobre el control, entre los aspectos más importantes.

El sistema define los componentes del control. en control interno y externo. reordenando y sistematizando los diferentes órganos de control dispersos en las entidades, logrando coherencia y oportunidad en el control que efectúe el organismo superior de control y los organismos conformantes del Sistema Nacional de Control.

El funcionamiento del Sistema Nacional de Control, se basa precisamente en el control interno permanente cuya labor es previa, concurrente o posterior, con carácter sistemático; y el control externo, que es selectivo, con enlace 
permanente con el control interno, que dicta las normas y procedimientos que regulan sistemáticamente la acción de ambos controles, cuya función recae en la Contraloría General como cabeza del sistema.

La ley del Sistema Nacional de Control establece una Contraloría, autónoma orgánica y funcional, con independencia del Poder Ejecutivo, con autoridad para ejercer el control en todas las entidades de la Organización del Estado como garantía que debe prestar al país sobre los actos administrativos en todos los niveles de la administración pública.

Además se debe considerar que el control moderno requiere de cambios consistentes en un control positivo, creativo y constructivo en busca del perfeccionamiento de la administración, orientado a un buen uso de los recursos del Estado.

\section{2.- Atribuciones Constitucionales del} Sistema Nacional de Control.- La legislación establece que el Sistema Nacional de Control y la Contraloría General de la República tienen atribución para conocer. en primera y última instancia administrativa los procesos de determinación de responsabilidades contra los funcionarios que administran los fondos y recursos públicos, así como su facultad de aplicar las sanciones correspondientes.

Sobre esta atribución se han formulado apreciaciones encontradas, las que consideran que la Contraloría no debe ser juez y parte, ya que al efectuar los informes que originan el inicio de procesos de determinación de responsabilidades, mantiene todo el circuito del control y la facultad sancionadora.

Los antecedentes de esta facultad se remontan a las atribuciones del Tribunal Mayor de Cuentas , creada el año 1607 a pedido del virrey don Francisco Toledo, denominado Tribunal y Audiencia Real de Cuentas. que efectuaba los exámenes y juzgamientos de las cuentas que funcionaban en el Perú ( 17 Cajas Reales), La Paz, Potosí, Oruro, Carangas. Buenos Aires y Jujuy.

La citada denominación posteriormente fue cambiada por "Contaduría General de Cuentas" hasta el inicio de la República.

En la Constitución del año 1832, el artículo 152 la denomina "Contaduría General", y el artículo señala que se reglamente "el modo de rendir y liquidar las cuentas". Por Decreto Supremo del 13 de octubre de 1826 es denominada "Contaduría General de Valores, Cobro y Distribución de Hacienda", revisa sus atribuciones, procedimientos y personal.

Por Ley del 02 de enero de 1840 , se estableció el nombre de "Tribunal de Cuentas", encargada como única oficina para el juzgamiento de las cuentas.

La ley de Contabilidad de los Ministerios del 30 de octubre de 1895 , establece en su artículo $1^{\circ}$ : "Cada Ministerio habrá de cerrar el 30 de junio y 31 de diciembre, y pasar dentro de los 15 días posteriores, al Tribunal Mayor de Cuentas para el examen y juzgamiento, la cuenta comprobada del semestre vencido: debiendo contestar por el mismo los reparos que el tribunal deduzca, acerca del gasto ordenado. Los Contadores serán responsables por la exactitud y buen orden de la cuenta, así como por su debida comprobación". 
La ley de 26 de noviembre de 1903 autoriza al Poder Ejecutivo para que efectúe las reformas que juzgue convenientes en el Tribunal Mayor de Cuentas, creándose una sección encargada del examen de la contabilidad consular e incrementando personal para el examen preferente de la contabilidad de aduanas. Aprobándose el "Reglamento Orgánico del Tribunal Mayor de Cuentas" mediante D.S. del 30 de abril de 1908, se fija el personal (un presidente, siete vocales. un fiscal. diez contadores, un contador rectificador; etc.). y otros cargos: estableciéndose significativas modificaciones en la organización y funciones, simplificando sus procedimientos y emisión de fallos de inmediata eficacia.

Con la finalidad de reformar el Tribunal y que éste logre mayor independencia. por D.S. del 26 de setiembre de 1929. se crea en el Ministerio de Hacienda una reparticipación administrativa, "Contraloría General de la República", conformada por las Direcciones del Tesoro, Contabilidad y Crédito Público. con funciones orientadas a un severo control de los gastos públicos antes del pago de los libramientos y fiel cumplimiento de las disposiciones sobre ejecución presupuestal.

Por la Ley Orgánica del Presupuesto Funcional de la República $\mathrm{N}^{\circ}$ 14816. en su artículo $68^{\circ}$ inciso $9^{\circ}$, se establece que "En el ejercicio de sus funciones de control, corresponde a la Contraloría ejercer la atribución de juzgar. en vía administrativa y a través del Tribunal de Cuentas de las entidades del sector público nacional" y el artículo 82 establece que "El Tribunal Mayor de Cuentas a que se refiere la Ley 8049 , es un organismo integrante de la Contraloría General de la República".

Atribución retomada en el D.L. $\mathrm{N}^{\circ}$ 19039 Ley Orgánica del Sistema Nacional de Control, que en el art. 13, inciso d, señala "Declara las responsabilidades en que hubieran podido incurrir los servidores del sector público en el ejercicio de sus funciones, aplicar sanciones y denunciar al Poder Judicial los hechos susceptibles de ser calificados como ilícitos con el objeto que se determine la responsabilidad civil o penal". El capítulo V del D.L. 19(139 señala “ De las responsabilidades y sanciones derivadas del proceso de control", reglamentado en el capítulo VI del D.S. N 001.72-C.G: que precisa sobre los alcances del proceso de determinación de responsabilidades.

Se establece de los antecedentes legales que es atribución del Sistema Nacional de Control y de la Contraloría General de la República, conocer en primera y última instancia administrativa los procesos de determinación de responsabilidades contra los funcionarios públicos, así como su facultad de aplicar sanciones; función que no debe ser delegada, sino que requiere de mayor difusión sobre los procedimientos y garantías que tienen los rindentes involucrados en los procesos abiertos por la Contraloría General como resultado de los informes de control del Sistema Nacional de Control.

\section{3.- Leyes del Sistema Nacional de} Control.- Cabe señalar que previamente a la creación del Sistema Nacional de Control, se dictó el Decreto Ley N ${ }^{\circ} 18750$ de Reorganización de la Contraloría General de la República (20.1.71) en 
cuyo considerando señala los aspectos siguientes:

a). Asegurar su autoridad y total independencia.

b). Control técnico con personal idóneo.

c). Labor moralizadora en la actividad pública.

d). Proceso integral del control.

e). El contralor general de la República, asume la categoría de Ministro de Estado.

\subsection{Principales aspectos del Decreto}

Ley $N^{\circ} 19039 .-$ El Decreto Ley $N^{\circ} 19039$ del 16 de noviembre de 1971. en resumen contiene lo siguiente:

Capítulo I Del Control de la actividad Pública.

Capitulo II Del Control Previo

Capítulo III Del Control Posterior

Capítulo IV De la Contraloría General de la República

Capítulo V De las Responsabilidades y Sanciones derivadas del Proceso de Control.

El Decreto Supremo $\mathrm{N}^{\circ}$ 01-72 CG reglamenta el Decreto Ley $\mathrm{N}^{\circ} 19039$ (7-3-72)

Principales aspectos:

- Creación del Sistema Nacional de Control señalando su ámbito, organización y procesos de control de la actividad pública.

- Reconocimiento de la Contraloría General de la República como entidad superior de control del sector público nacional. Es autónoma en el ejercicio de sus funciones con independencia administrativa y funcional.

- Reconocimiento del Contralor General de la República como el funcionario superior de control, no sujeto a mandato imperativo de ninguna entidad.

- Delineamiento de las funciones del control interno y dependencia directa de la máxima autoridad de la entidad.

- Establecimiento de que ningún informe de auditoría será emitido en forma definitiva sin dar oportunidad a los responsables de la gestión para presentar las pruebas documentadas de descargo.

- Participación del Contador Público Colegiado en la dirección, supervisión y emisión de los informes de auditoría.

- Establecimiento del ámbito de control que cubre toda la actividad pública mediante acciones de control previo y verificación posterior de la correcta administración de recursos humanos, materiales y financieros, y de resultados de gestión pública.

Este Decreto Ley, entre otras funciones de la Contraloría General, señala las siguientes:

* Ejercer el control posterior externo de los actos y procesos de las entidades del sector público. así como de la utilización de los fondos públicos que efectuén las entidades privadas. Esta atribución de control se realiza al examinar los actos y procesos de las entidades del sector público nacional, y utilización de los fondos públicos y bienes por parte de otras entidades. Este control por su técnico debe ser ejecutado preferentemente mediante auditorías y exámenes especiales, concordante, con la política de control establecida por el Contralor General.

* Informar previamente sobre las operaciones, finanzas, avales y otras garantías que otorgue el Estado, así como 
los proyectos de contratos que comprometan su crédito y capacidad financiera.

* Control del cumplimiento de las disposiciones legales y reglamentarias, y de la veracidad de gasto público.

* Declarar responsabilidades de los servidores del sector público como resultado de los informes; aplicar sanciones y denunciar ante el Poder Judicial sobre presuntos indicios razonables de delito, para que determine la responsabilidad civil y/o penal.

Dictado de Normas Técnicas de Control a seguir en el Proceso de Control.

El sistema nacional de control, para efectuar el proceso integral del control, precisa del cumplimiento de la normatividad, que son las leyes, reglamentos, normas técnicas de control y normas de los sistemas administrativos, las que son verificadas en las auditorías y exámenes especiales.

Las normas técnicas dictadas por la Contraloría General son disposiciones fundamentales que regulan el funcionamiento del control y evaluación de la gestión, las mismas que se complementan con las normas dictadas por los demás sistemas administrativos y las emitidas por las entidades. El incumplimiento de estas normas, debidamente evaluadas, motivan las acciones correctivas por la administración y también sanciones por irregularidades cometidas.

Las normas técnicas de control incluyen las normas técnicas de control interno y las normas técnicas de auditoría dictadas a partir del año 1972 y que se han dejado sin efecto con la Resolución de Contraloría No 196-88-CG del 18 de julio de 1988. Reglamento de las acciones de control, cuya vigencia ha continuado en parte después del Decreto Ley $\mathrm{N}^{\circ}$ 26162, por la falta de reglamento de ésta.

Sin embargo, es importante mantener y perfeccionar las normas técnicas de control por ser las disposiciones que orientan y uniforman los criterios de control de las entidades y del personal del sistema nacional de control en el proceso de control. como lo establece el inciso b) del Art. 12 del Decreto Ley 19039.

Adopción de medidas temporales, como resultado de una auditoría en una entidad para garantizar la adecuada determinación de responsabilidades, situación que no ha tenido aplicación.

Remitir al titular de la entidad y del sector copias sobre la apertura del proceso de determinación de responsabilidades, así como de las resoluciones definitivas.

Presentar un informe de auditoría que es remitida con la cuenta general al Congreso por el Presidente de la República, de conformidad con lo establecido en el Art. 200 de la Constitución del año 1979.

El informe sobre la cuenta general debe contener la opinión de la Contraloría General, la que se sustenta con los informes de auditoría y exámenes especiales efectuados por el sistema nacional de control sobre la información financiera y gestión administrativa del sector público nacional

Informar sobre nuevos dispositivos de control, así como dictar 
disposiciones que aseguren el proceso integral de control.

Informar previamente sobre las operaciones financieras, avales y otras garantías que otorgue el Estado; las que se efectúa en base a los expedientes que contienen los informes de los organismos técnicos y de las autoridades administrativas.

El pronunciamiento es sobre el cumplimiento de la formalidad del procedimiento de encontrarse de acuerdo a las normas legales, en señal de lo cual se efectúa la visación del proyecto.

Esta participación de informar previamente sobre las citadas operaciones, están sujetas al control posterior del sistema.

$\mathrm{Al}$ respecto, en los proyectos de ley que se presentaron al Congreso antes del Decreto Ley $\mathrm{N}^{\circ} 26162$ no se mencionan los términos Auditoría ni auditor en los capítulos dedicados a las funciones de la Contraloría General ni en otros capítulos, a excepción de un anteproyecto del año 1990 preparado por el Colegio de Contadores Públicos de Lima.

3.2 Principales aspectos del Decreto Ley $N^{\circ}$ 26162.- Este Decreto Ley $\mathrm{N}^{\circ} 26162$, publicado el 30 de diciembre de 1992, Ley del Sistema Nacional de Control, deroga el Decreto Ley ${ }^{\circ} 19039$.

En resumen el Decreto Ley $\mathrm{N}^{\circ} 26162$ contiene lo siguiente;

Titulo I Creación del Sistema y Ambito Titulo II Del Control Gubernamental, Principios y Criterios.

Capítulo 1 Del control gubernamental Capítulo 2 Principios y criterios del control gubernamental.

Título III Atribuciones del sistema nacional de control

Titulo IV Organos del sistema nacional de control

Título V Recursos del sistema nacional de control.

Disposiciones Transitorias

Disposiciones Finales

Los principales aspectos del Decreto Ley $\mathrm{N}^{\circ} 26162$, se comentan en sus artículos siguientes:

$1^{\circ}$ Finalidad del sistema nacional de control.

"Supervisar la correcta, útil, eficiente, transparente utilización de los bienes y recursos públicos y el ejercicio de las funciones de los empleados públicos, en relación a los resultados obtenidos y al cumplimiento de la normatividad.

$2^{\circ}$ Conformación del sistema nacional de control. Composición:

a).-La Contraloría General de la República.

b).-Auditoría del Poder Ejecutivo.

c).-Auditoría del Poder Judicial.

d).-Auditorías Sectoriales del Poder Ejecutivo.

e).-Auditorías Regionales

f).- Auditorías de Municipalidades

g).-Auditorías de Organismos Autónomos

h).-Auditorías de Instituciones y personas de derecho público

i).- Auditorías intemas de empresas que conforman la actividad empresarial del Estado a que alude el literal d) del artículo $3^{\circ}$ de esta ley.

$3^{\circ}$ Entidades sujetas al Sistema Nacional de Control

- El Gobierno Central y los Gobiernos Regionales y Locales.

- Las unidades administrativas del Poder Legislativo y del Poder Judicial.

- Los Organismos Autónomos creados por la Constitución Política y las instituciones y personas de derecho público. 
- Las empresas integrantes de la actividad empresarial del Estado con excepción de las empresas de economía mixta y accionariado del Estado.

- Las entidades privadas por los recursos públicos que perciban.

\section{$15^{\circ}$ Control gubernamental}

Consiste en la verificación periódica del resultado de la gestión pública, a la luz del grado de eficiencia, eficacia transparencia y economía que hayan exhibido en el uso de los recursos públicos, así como del cumplimiento por las entidades de las normas legales y de los lineamientos de política y planes de acción. Evalúa la eficacia de los sistemas de administración y control y establece las causas de los errores e irregularidades para recomendar las medidas correctivas.

\section{$6^{\circ}$ Control gubernamental}

Es interno y externo, siempre selectivo y posterior.

Control Interno Previo

En competencia exclusiva de las entidades, detalladas en el art. $3^{\circ}$.

\section{$8^{\circ}$ Control Interno Posterior}

Es ejercido por los responsables superiores del servidor o funcionario ejecutor en función de los procedimientos de control emanados por el titular de la misma respecto de los resultados de las operaciones bajo su competencia y por el auditor en función a sus planes y programas anuales. Este control debe evaluar no sólo los aspectos administrativos del uso de los recursos sino evaluar la gestión en función de las metas y programas trazados.

\section{$9^{\circ}$ El Titular y Directores}

Son responsables de Supervisar el Control Interno previo y el Control Interno posterior para evaluar la gestión. $10^{\circ}$ Los Organos internos de Control Efectúan el control posterior mediante auditorías y exámenes especiales.

\section{$11^{\circ}$ Control Externo}

Consiste en el conjunto de políticas, normas, métodos y procedimientos técnicos aplicados por la C.G.R. y/o por los órganos del sistema que ejercen control gubernamental y las sociedades de auditoría independiente que ésta designe y se contrate para evaluar la gestión , la captación y el uso de los recursos públicos por ellos. Se efectúa mediante auditorías y exámenes especiales.

\section{$12^{\circ}$ Acción de Control}

Se denomina acción a la que desarrolla el personal de los órganos del sistema o contratados por este $\mathrm{y} / \mathrm{o}$ el de las sociedades de auditoría independientes designadas y contratadas para tal fin para dar cumplimiento mediante la aplicación de un conjunto de procedimientos y métodos de trabajo a las atribuciones que le confiere la presente Ley.

Tales atribuciones se efectúan siguiendo el Plan Nacional de Control y los Planes aprobados para cada órgano del Sistema y se realizan de acuerdo a su programación interna de operaciones y/o en base a los requerimientos de la Contraloría General de la República.

$13^{\circ}$ Principios que guían el ejercicio del Control Gubernamental.

La universalidad. esto es la potestad de los órganos que integran el sistema. dentro de los límites de sus respectivas competencias, de efectuar el control respecto de todas las actividades de la entidad en la que están adscritas, así como de todos sus servidores y funcionarios, cualquiera fuere su jerarquía. Esta potestad no excluye la posibilidad de que 
el órgano de control superior ejercite acción de evaluación sobre el órgano de control que ejecuta dicha acción y sobre las recomendaciones emitidas por éste para supervisar su cumplimiento o sobre la entidad a solicitud de la Contraloría General de la República.

El carácter integral, es decir, que el control consta de un conjunto de acciones destinadas a evaluar los beneficios económicos y/o sociales obtenidos en relación con el gasto que han originado tomando en cuenta las metas cualitativas y cuantitativas establecidas por la entidad, su vinculación con las políticas gubernamentales y los índices de eficiencia históricos de la misma.

La autonomía funcional y económica, expresada tanto en la potestad de los órganos de control de organizarse, administrarse y ejercer sus funciones de manera independiente en cuanto un manejo económico autónomo.

El carácter técnico y especializado del control.

La publicidad, consistente en la difusión periódica, con finalidad ejemplificadora, de los resultados de las acciones de control de mayor importancia.

La atribución para acceder a todo tipo de información y examinar registros y operaciones de todo índole.

La no interrupción del funcionamiento del ente examinado al efectuar una acción de control.

La materialidad o significación económica, es decir, la concentración del control en las transacciones u operaciones de mas significación en la entidad examinada.

Objetividad, las acciones de control deben realizarse sobre la base de una evaluación de los hechos rodeados de imparcialidad que eviten la subjetividad.

$14^{\circ}$ Criterios que orientan el ejercicio del Control.

La oportunidad, de modo que las acciones de control se realicen en el momento debido.

La colaboración, de manera que la actuación de los órganos de control esté fundamentalmente dirigida a cooperar con las entidades, a fin de que perfeccionen sus sistemas técnicos administrativos y logren sus metas.

La horizontalidad, en virtud de la cual las entidades no están subordinadas jerárquicamente a los órganos de control.

La reserva, que impide que durante la ejecución del control se revele información que cause daño a las entidades, a su personal o al Sistema, o dificulte la tarea de este último.

La flexibilidad, según la cual al realizarse el control ha de otorgarse prioridad al logro de las metas propuestas.

La especialización, que considera la necesidad de efectuar el control en función de la naturaleza de la entidad en la que incide. Para lo cual, los diversos órganos del Sistema propondrán a la Contraloría General de la República sus recomendaciones para la elaboración de las normas técnicas especializadas de control que consideren aplicables a sus entidades.

La presunción de licitud, según la cual, salvo prueba en contrario, se reputa que los servidores y funcionarios sujetos a control han actuado con arreglo a las normas legales y administrativas en forma transparente. 
$16^{\circ}$ Atribuciones del Sistema Nacional de Control

Efectuar por conducto de sus órganos la verificación de la correcta gestión y utilización de los recursos públicos dentro de los objetivos y planes de las entidades a que se refiere el artículo 3 de esta Ley y supervisar la ejecución de los presupuestos del sector público, de las operaciones de la deuda pública.

Formular recomendaciones para mejorar la capacidad y eficiencia de las entidades en la toma de decisiones y en el manejo de sus recursos, así como los procedimientos y operaciones que emplean en su accionar, a fin de optimizar sus sistemas administrativos, de gestión $\mathrm{y}$ de control interno.

Establecer los procedimientos para que todo titular de una entidad sujeta a la presente Ley rinda cuenta oportuna de los resultados de su gestión.

Propugnar la capacitación permanente de los servidores y funcionarios públicos.

Exigir a los servidores y funcionarios públicos la plena responsabilidad por sus actos en la función que desempeñan, determinando el tipo de responsabilidad incurrida, sea administrativa, civil o penal y recomendando la adopción de las acciones necesarias preventivas, de validación, correctivas o sancionadoras o ejecutándolas en caso de incumplimiento.

Considerar que los informes y/o dictámenes resultado de una acción de control emitidos por cualquier órgano del Sistema constituyen prueba preconstituida para la iniciación de las acciones administrativas y/o legales a que hubiera lugar. Los diversos órganos del sistema ejercen estas atribuciones y las que expresamente se les señalan en esta Ley y sus normas reglamentarias, con excepción de la ejecución de las sanciones que es potestad de la Contraloría General de la República, en su calidad de última instancia del sistema.

$17^{\circ}$ La C.G.R., órgano rector del Sistema Nacional de Control

Ratifica su autonomía técnica, funcional, administrativa y financiera.

$19^{\circ}$ Atribuciones de la Contraloría General de la República.

Tener acceso en cualquier momento y sin limitaciones a los registros, documentos e información de las entidades, aún cuando sean secretos.

Requerir a los órganos de control del Sistema que dispongan la realización de acciones de control, auditorías u otros exámenes que a su juicio sean necesarios o ejercer en forma directa el control externo posterior sobre cualquiera de los actos de cualquier entidad sujeta al ámbito de esta Ley,

Recomendar a los titulares de la entidad la aplicación de las sanciones al auditor, en la forma que permita la legislación, en los casos en que se le encuentre parcialización con la entidad, un deficiente ejercicio profesional o disponer la sanción directamente en caso de incumplimiento.

Requerir la presencia de toda persona natural o los representantes de cualquier persona jurídica que considere necesario bajos los apremios que la Ley señala para los testigos.

Supervisar y garantizar el respeto y cumplimiento de las observaciones, recomendaciones y sanciones que sean propuestos sobre las base de los informes de control emanados de cualquiera de los órganos del sistema. Para efectuar esta 
labor puede dirigirse al titular de la entidad de la que depende sectorial 0 funcionalmente la entidad objeto de la recomendación a efecto que amerite su cumplimiento bajo apercibimiento de sancionar directamente en caso de incumplimiento.

En los casos de comprobación de responsabilidad civil o penal, es decir, la existencia de daño económico o presunción de acto ilícito, ordenará la adopción de las acciones legales, bajo sanción de que proceda la destitución del titular de la entidad.

En los casos en que la Contraloría en la ejecución directa de una acción de control encuentre daño económico o presunción de acto doloso, puede disponer que el Procurador Público o el representante legal que corresponda a la entidad examinada inicie las acciones legales pertinentes en forma inmediata.

Velar por la adecuada implantación de los órganos de control integrantes del sistema, proponiendo a las entidades el fortalecimiento de dichos órganos con personal calificado e infraestructura moderna necesaria para el cumplimiento de sus fines. Para tal efecto existen disposiciones sobre requisitos mínimos para ser auditor en función de la especialidad de las entidades.

Auditar anualmente la Cuenta General de la República, emitiendo el correspondiente dictamen.

Formular recomendaciones que promuevan reformas sobre los sistemas administrativos de las entidades sujetas al sistema.

Aprobar los planes y programas anuales de control de las entidades sujetas al sistema.

Capacidad de rechazar los informes y/o dictámenes de los órganos del sistema y de personas naturales o jurídicas contratadas o sociedades de auditoría designadas que no se ajusten a las normas de control o que no hayan cumplido el trabajo encomendado, en cuyo caso dará las instrucciones precisas para superar las deficiencias.

Establecer responsabilidad a los titulares de las entidades sujetas al Sistema que violen la independencia de sus órganos de su control.

$20^{\circ}$ Contralor General de la República Funcionario de mayor rango del Sistema Nacional de Control no sujeto a dependencia alguna.

$21^{\circ}$ Nombramiento y renovación del Contralor General de la República, según el Art. $82^{\circ}$ de la Constitución vigente.

$22^{\circ}$ Requisitos para ser Contralor General Ser peruano de nacimiento

Gozar del pleno ejercicio de los derechos civiles.

Tener al tiempo del nombramiento no menos de 40 años de edad.

Tener Título profesional.

Tener un ejercicio profesional no menor a 10 años.

$23^{\circ}$ Impedimentos para ser Contralor General.

$24^{\circ}$ Atribuciones y deberes del Contralor General de la República.

Planificar las acciones de control del sistema.

Dictar normas técnicas de control. 
Aprobar los planes o programas anuales de control.

Ordenar auditorías y exámenes especiales.

Constituirse en última instancia administrativa.

Sancionar en los casos de incumplimiento de las recomendaciones formuladas en las acciones de control.

Formular. a través del Procurador público, denuncias ante el Ministerio Público y/o acciones judiciales.

Capacidad de solicitar todos los documentos que sustenten los informes, que se deben guardar por un período de diez años;

Otros.

$25^{\circ}$ Vacancia del cargo de Contralor General.

$26^{\circ}$ Vacancia por falta grave del Contralor General de la República.

$27^{\circ}$ Juicios al Contralor General de la República, el procedimiento es igual al de los Ministros de Estado,

$28^{\circ}$ El titular de la Contraloría, el Subcontralor y los jefes de los órganos de control del sistema, están prohibidos de ejercer actividad lucrativa y participar en cualquier entidad pública o privada, excepto la docencia.

$29^{\circ}$ Emisión de Resoluciones de Contraloría.

$30^{\circ} \mathrm{El}$ segundo funcionario del sistema , es el Subcontralor General de la República. $31^{\circ}$ Mantenimiento del valor constante del presupuesto de la Contraloría General de la República, en relación al monto aprobado en el año anterior.

$32^{\circ}$ El Congreso puede efectuar auditorías o exámenes especiales a la Contraloría General de la República a través de auditores independientes.

\section{Disposiciones Legales.}

$1^{\circ}$ Definiciones básicas:

- Recurso público

- Servidor o funcionamiento público

- Gestión pública

- Fondos públicos

- Control de legalidad

- Control de gestión

- Responsabilidad administrativa

- Responsabilidad civil

- Responsabilidad penal.

$2^{\circ}$ Creación de la Escuela Nacional de Control, facultad a otorgar grados académicos de Magister, está comprendida en el Art. 99 de la Ley 23733, Ley Universitaria.

3.3 Aspectos técnicos legales necesarios en la normatividad del Sistema Nacional de Control.- La normatividad debe asegurar que el Sistema Nacional de Control y su entidad rectora para cumplir con las atribuciones señalados en la Constitución, cuente con regulación clara $y$ precisa que perfeccione permanentemente la actividad de control

(1) Facultad de declarar responsabilidades y determinar sanciones como consecuencia de las acciones de control. De la revisión del D.L. $\mathrm{N}^{\circ} 26162$ se determina que dentro de las atribuciones de los diversos órganos del Sistema Nacional de Control el art. 16 inciso f) establece que, como consecuencia de los informes de las acciones de control 
emitidos por los órganos del sistema, éstos constituyen pruebas preconstituida para el inicio de acciones administrativas y/o legales.

Al respecto, la anterior Ley del Sistema Nacional de Control No 19039 , que dedicaba el Capítulo V De las Responsabilidades y Sanciones del Proceso de Control, no ha sido retomada, quedando en consecuencia limitada la acción del Organo Superior de Control a la ejecución de sanciones, en su calidad de última instancia del Sistema después de las acciones administrativas iniciadas por la entidad examinada como 10 establece el inciso f) del artículo 24 del Decreto Ley N" 26162.

La misión que confiere la Constitución a la Contraloría General para que controle y resguarde la corrección del manejo de la cosa pública, se materializa a través de la ejecución del proceso integral de control, cuyas etapas fundamentalmente están constituida por la ejecución del trabajo de campo y la aplicación de las medidas correctivas, encontrándose en esta última la declaración de responsabilidades y determinación de las sanciones.

El proceso de determinación de responsabilidades se sustenta en el rol moralizador que demanda la tarea del control, que tiene como fundamento jurídico la obligación del funcionario y servidor del Estado a efectuar la rendición de cuentas de su gestión y de la utilización de los recursos públicos confiados a su administración, exigiendo un deslinde de responsabilidades por los hechos irregulares y deficiencias que afectan los intereses de la Nación, asimismo se preve la instancia plural y la motivación como principios rectores de su procedimiento.
El proceso de determinación de responsabilidades se constituye así en parte primordial del proceso integral de control, cuyo tratamiento y procesamiento, es de carácter técnico y especializado del control, considerado como principio del control gubernamental, por lo que debe conducirse dentro del sistema nacional de control.

El control es ajeno en la toma de decisiones a factores o circunstancias políticas que interfieran en su función. Sobre esta situación. la legislación de diversos países contempla la responsabilidad y sanciones de los funcionarios por parte del Organo Rector de Control, tal como son los casos de las Repúblicas de Argentina, Brasil, Bolivia, Chile, Ecuador, Nicaragua, Uruguay, Venezuela, etc.

(2) Independencia económica y presupuestal.

El control fiscal moderno no admite que una Institución Fiscalizadora Superior no cuente con independencia económica que garantice su autonomía técnica y funcional, así como la ejecución normal de los programas de control.

A nivel mundial y latinoamericano a través de los Congresos del INTOSAI e ILACIF, se ha recomendado la necesidad de que los organismos supervisores de control gocen de independencia económica para su funcionamiento, así tenemos países como Argentina, Chile, Ecuador, Panamá y Puerto Rico que han considerado en sus respectivas Leyes de Control esta autonomía, lo cual le evita recortes en sus presupuestos por los órganos de la administración pública que están sujetos a su control.

La falta de recursos ha incidido negativamente en la operatividad de la 
Contraloría General, lo cual ha sido una constante, que no debe repetirse en consideración de la autonomía constitucional, lo cual significa clarificar especialmente el artículo 33 del Decreto Ley $N^{\circ} 26162$ que señala una limitación al tener que sujetarse la elaboración del Presupuesto de la Contraloría General dentro del marco establecido por el Ministerio de Economía y Finanzas.

Es de señalar que la Contraloría, debe contar con los recursos presupuestales que le permitan cumplir no sólo con su programación de control, sino proyectarse como una entidad modelo a seguir en todo orden, especialmente de su personal, que debe ser bien remunerado y a dedicación exclusiva; con permanente capacitación, orientado a la formación de cuadros con alto grado de especialización, y experiencias necesarias en todos los niveles de la organización. Además contar con infraestructura, equipos y tecnología avanzada.

(3) Control previo de los contratos con financiamiento externo y fiscalización de la deuda pública.

Es necesario considerar la atribución concordante con el artículo 82 de la Constitución, de ejercer formalmente el control previo de las Bases de Licitaciones y de los Contratos de estudios y ejecución de proyectos con financiamiento, con la finalidad de cautelar que los mismos prevean con idoneidad los mecanismos y procedimientos que garanticen beneficios al Estado, cuyos recursos se comprometen significativamente. Referencia inciso 1) Art. 12 del D.L. No 19039.

Este mecanismo de control está incluido, entre otros, en la legislación ecuatoriana y de otros países y obedece a la incontrovertible necesidad de evitar, con la presencia de la Contraloría General en los proyectos de gran envergadura, situaciones irreparables para el Estado en materia de contratación pública.

(4) Definición de la Competencia y facultades de la Contraloría General.

En concordancia con el Art. 82 de la Constitución política y la naturaleza de la misión que se le encomienda al Sistema Nacional de Control, y a la Contraloría General como órgano rector, se exige se amplíe los alcances de la ley y su reglamento, que necesariamente deben definir con claridad y objetividad las atribuciones sobre la materia financiero presupuestal, deuda pública y gestión; así como utilización de bienes y recursos públicos que corresponde al Organismo superior de control.

Esta definición precisará su ámbito de competencia en el ejercicio funcional, para lo cual el criterio rector está dado por los intereses del Estado, sometidos a su tutela jurídica, cualquiera sea el régimen legal o económico de sus instituciones, así como las atribuciones incuestionables que permitan efectivizar el cumplimiento cabal de sus funciones.

(5) Celeridad de los Procedimientos de Control

Las funciones de los órganos de control son de carácter posterior, por tanto es necesario incorporar en la nueva legislación procedimientos que cautelen la celeridad y economía de las acciones de control para garantizar la oportunidad debida de sus resultados, considerando asimismo, los mecanismos procesales para que los servidores sujetos a control presenten documentación de descargo y ejerciten su derecho de defensa.

Por los fundamentos técnicos doctrinarios, se desprende la necesidad de 
ampliar los alcances de la nueva ley, a regular a través de su reglamento debidamente compatibilizado, con los dispositivos que regulan el comportamiento de todos los motores del Estado.

\section{4.- Elementos fundamentales del proceso integral del Sistema Nacional de} Control.- Aseguran el proceso integral del control administrativo y financiero, el logro de metas y resultados en la administración del Estado, los tres elementos fundamentales que se describen a continuación:

a) La normatividad.- está conformada principalmente por lo siguiente:

-La Constitución Política.

-Ley del Sistema Nacional de Control y su Reglamento.

-Leyes de Presupuestos.

-Leyes Orgánicas de las entidades del

Gobierno Central; Instituciones públicas y organizaciones autónomas.

-Ley General de Sociedades.

-Leyes de las Empresas del Estado.

-Ley de la actividad empresarial.

-Ley de promoción de la inversión privada en las empresas del Estado.

-Normas técnicas de control.

-Normas de los sistemas administrativos.

-Otras normas relacionadas con el control.

b) Los Organos de Control

Está conformada por los organismos siguientes:

-La Contraloría General, Organismo Rector del sistema.

-Los Organos de Auditoría, de las entidades sujetas al Sistema, (con diversas denominaciones, oficinas de auditoría interna, inspectorías generales, oficinas de control interno, etc., hasta la promulgación del Decreto Ley $\mathrm{N}^{\circ}$ 26162).

c) Los métodos y procedimientos.- son los medios empleados en la ejecución del control, principalmente los siguientes:

-Aplicación de los principios administrativos que constituyen los postulados que uniforman el proceso integral de la administración de las entidades o sistemas con relación a los elementos de la Administración : planeamiento. organización, dirección .o ejecución y control.

- Aplicación en las entidades de los principios básicos de control interno que constituyen los postulados que uniforman los métodos. procedimientos y prácticas que permiten una adecuada organización y mantener un sólido sistema de control interno administrativo y financiero . El control interno, cuya base se encuentra en el concepto de carga y descarga de responsabilidades y deberes de los que asumen la gestión.

-Auditoría y exámenes especiales efectuados por los órganos internos de la propia entidad.

-Auditorías y exámenes especiales efectuados por la Contraloría General y Organos del sistema y las sociedades de auditoría independientes designadas.

5.- Funcionamiento del Sistema Nacional de Control.- El Sistema Nacional de Control está conformado por la Contraloría General y los Organos de Control Interno, existentes en las entidades. El funcionamiento del sistema se basa en las atribuciones y ubicación de sus órganos conformados, así tenemos:

La Contraloría General, como órgano superior del sistema, realiza el control externo, el mismo que es selectivo 
en consideración al ámbito que integran las entidades del sector público nacional.

En cautela del control integral, la Contraloría General dicta normas, métodos, procedimientos, directivas, lineamientos de control, etc., que deben ser cumplidas por los integrantes del sistema y de las entidades.

En la determinación de las acciones de control son importantes los lineamientos generales y especiales a ser aplicados en control de las entidades, que se concretan con la formulación de los planes y programas anuales de control, lo que permite coherencia entre los diversos niveles de los órganos de control, es decir, nivel institucional, sectorial y regional.

La consolidación de los planes de control por la Contraloría General, por sectores y regiones, evita duplicidad de esfuerzos del sistema y agiliza el seguimiento del cumplimiento oportuno de los planes y programas anuales de control, que se materializan al recepcionar copias de los informes emitidos por los órganos internos de control, los mismos que son evaluados técnicamente, para efectos de la adopción de acciones que motiven el contenido de dichos informes.

La Contraloría General de la República tiene la atribución de elaborar los planes y programas anuales de control, así como la capacidad de rechazar los informes y/o dictámenes de los órganos del sistema.

Los órganos del sistema. ubicados en la organización de las entidades dependientes administrativamente de la máxima autoridad de la entidad y funcionalmente de la Contraloría General, realizan el control interno posterior, el mismo que es permanente en el ámbito de la entidad a la que pertenece. Como elemento integrante del sistema cautela el cumplimiento de la normatividad dictada por el organismo superior de control.

El funcionamiento del sistema se efectúa con el cumplimiento de los planes y programas nacionales de control, con los ajustes propios durante el desarrollo de la labor, y remitiendo en su oportunidad, los informes a la Contraloría General y al titular respectivo.

Actualmente, las acciones de los órganos internos de control dependen del apoyo y receptividad del titular de la entidad, por lo que considera que siendo vital para el sistema, además del jefe del órgano interno de control, debe ser designado por la contraloría general, correspondiendo a un profesional en auditoría con experiencia en el sector público nacional, y otras cualidades propias que aseguren la efectividad del control de las entidades, se supervise con mayor frecuencia el desarrollo de sus actividades , así como su independencia y efectivo apoyo del titular de la entidad en cumplimiento al inciso e) del art. $19^{\circ}$ del Decreto Ley $\mathrm{N}^{\circ} 26162$.

El jefe del órgano interno de control es el funcionario de control, representante permanente del Contralor General en la entidad, y como tal su independencia profesional es la mejor garantía del cumplimiento del artículo $82^{\circ}$ de la Constitución y demás normas del Sistema Nacional de Control.

La actual normatividad complementa lo señalado; que establece la estabilidad en el cargo del jefe del órgano interno de control, el que no puede ser removido sin previa opinión de la 
Contraloría General, aspecto que debe ser considerado en el reglamento.

\section{III.- ESQUEMA O'RGANIZATIVO DE UN MODELO DE CONTROL}

Para un modelo de control aplicado a un Estado moderno se adoptan los criterios básicos siguientes:

1.- Misión.- salvaguardar el patrimonio de la sociedad mediante la evaluación de la gestión de los resultados alcanzados en el manejo de los recursos públicos. que son propiedad del pueblo.

\section{2.- Objetivos:}

- Apoyar al Estado para que con eficiencia y eficacia logre bienestar para todos los miembros de la sociedad que representa. - Asegurar y apoyar que las funciones legislativas, ejecutivas y judiciales cumplan sus objetivos políticos, económicos y sociales con mayor transparencia y orientado a la justicia social plena.

-Salvaguardar que los sistemas administrativos, que incluyen los de planificación, organización, dirección control y tesorería se ejecuten con mejor eficiencia, economía y eficacia propendiendo a la eliminación de la corrupción administrativa.

\section{3.- Marco legal}

-El Sistema Nacional de Control debe ser normado a través de una Ley orgánica que le permita su autonomía funcional, administrativa, presupuestal y financiera; y -Debe dictarse normatividad que permita fortalecer las disposiciones referentes a la aplicación de penas y sanciones para los funcionarios que incurren en faltas y/o delitos en contra del Estado.
4.- Organización

El control en un Estado moderno, está conformado por los organismos siguientes:

-Poder Legislativo.- ejerce la fiscalización sobre los demás poderes del Estado, dictando la normatividad que le fija su competencia. Dicha fiscalización tiene como organismo técnico de ejecución a la Contraloría General de la República, que actúa en forma autónoma y como ente rector de los organismos de control interno, conformantes de la red del Sistema Nacional de Control.

-Poder Ejecutivo.- como parte de su acción administrativa, controla el cumplimiento de los planes y programas de desarrollo económicos y sociales a través de la supervisión. información estadística y contabilidad nacional.

- Poder Judicial.- presta apoyo al sistema nacional de control. estableciendo oportunamente la responsabilidad civil o penal que derive de las irregularidades o delitos detectados por los órganos de control.

-Medios de información y comunicación.en un sistema democrático los medios de información son elementos que contribuyen con las medidas de control, informando y divulgando los fraudes, desfalcos, corruptelas y despilfarros de los recursos del Estado, por lo que se constituyen en un efectivo colaborador de fiscalización y moralización.

5.- Recursos

Sobre los recursos se considera lo siguiente:

a).- Con la finalidad de asegurar la independencia económica de la Entidad Fiscalizadora Superior, el monto de sus 
recursos financieros necesarios deberá ser presentado a la Comisión del Presupuesto del parlamento para su sustentación y aprobación, lo cual permitirá el cumplimiento de sus objetivos. Este planteamiento será basado en un estudio realizado por la entidad superior de control de acuerdo a sus necesidades y planes trazados en cada ejercicio.

b).- Los recursos humanos deben ser del más alto nivel profesional, debidamente capacitados y adecuadamente remunerados.

c).- Deben contar con recursos materiales y tecnológicos que permitan al Organo Superior de Control informar en forma oportuna y eficiente a los poderes del Estado y a la ciudadanía sobre:

-Los resultados obtenidos en el accionar de su Plan Operativo Anual.

-Resultados en cuanto al uso de los recursos humanos, materiales financieros, tecnológicos, ecológicos y justicia social en los diferentes sectores del Estado.

Este modelo de Organización nos permite establecer las consideraciones siguientes:

* El organismo superior de control como sistema que realiza el control posterior externo e interno, mantiene autonomía funcional, económica y administrativa, que le permite cumplir sus objetivos y funciones sin limitaciones ni intromisión de ningún Poder, dado que la Comisión de Economía del Congreso aprueba el presupuesto propuesto.

* Apoya al Poder Legislativo como ente fiscalizador del Estado, coordina con el Poder Ejecutivo y Judicial en cumplimiento del control de la actividad pública.

* Las oficinas de Auditoría Interna conformantes del Sistema Nacional de Control, independiente del apoyo a la gestión de las necesidades económicas, efectúan acciones de control en apoyo entre otros, al Plan Global de Control del Sistema, para cautelar el manejo y uso de los recursos del Estado y la ejecución de la Auditoría de los Estados Financieros y Presupuestos para los fines del Informe y Opinión de la Cuenta General de la República.

*Cumple su rol de comunicar en forma periódica sobre los resultados de las acciones del Estado, a la ciudadanía.

*Informa oportunamente a los responsables de los organismos del Estado sobre aspectos importantes de los resultados de las acciones de control para la adopción de medidas correctivas orientadas a mejorar la gestión; así como el cumplimiento de las metas y objetivos bajo los criterios de economía, eficiencia, eficacia y equidad.

* Capacitar en forma permanente y en el más alto nivel nacional e internacional a los funcionarios conformantes del Sistema Nacional de Control y a los funcionarios de la Administración Pública.

La capacitación permitirá la mejor comprensión de las acciones de control frente a la administración, contribuyendo al desarrollo de un Estado moderno que administre apropiadamente sus recursos.

De lo expuesto anteriormente se establecen las ventajas y desventajas siguientes:

a).- Ventajas:

- Mantiene una autonomía sin limitaciones. 
- Permite una independencia económica $\mathrm{y}$ administrativa.

- Tiene jurisdicción en todo el ámbito del sector público nacional.

- Asegura resultados eficientes en las acciones de control.

- No está expuesto a los vaivenes políticos.

- Mayor confianza del contribuyente en el manejo de los recursos.

- Posibilita el cumplimiento de los objetivos nacionales con el consiguiente desarrollo social de la población, consolidando el bien común y justicia social.

- Ejercer un control técnico y oportuno que permita credibilidad en la población.

- Aplicación de sanciones oportunas a los funcionarios responsables que incurran en faltas y/o delitos.

b).- Desventajas:

- Existencia de grupos de poder interesados en evitar el perfeccionamiento del Sistema Nacional de Control.

- Deficiencia de la información financiera y presupuestal de las entidades públicas.

- Falta de interés de los funcionarios responsables en la implementación de las observaciones formuladas en los informes.

- Falta de sanciones oportunas o no resueltas por las instancias correspondientes, administrativas, civiles y penales.

\section{BIBLIOGRAFIA}

INCA GARCILASO DE LA VEGA.

1985. Comentarios Reales

Editorial Andina

Lima

LEY ORGANICA DEL SISTEMA NACIONAL DE CONTROL

Decreto Ley N 19039 del 16/11/71

Decreto Ley No 26162 del 24/12/92

CONTRALORIA GENERAL DEL PERU

1972-1975 Revista ILACIF

CONTRALORIA GENERAL DEL PERU

Revista Perú Control

CONTRALORIA GENERAL DEL PERU

1980 Diversas Conferencias sobre el Sistema Nacional de Control.

CONTRALORIA DE LOS ESTADOS UNIDOS DE NORTEAMERICA.

"Normas de Auditoría de Organismos, Programas, Actividades y Funciones Gubernamentales".

1972. Traducción: Contraloría General del Perú.

CONTRALORIA GENERAL DE LA REPUBLICA DE VENEZUELA

1976. Revista de Control Fiscal.

ILACIF

1990 Compendio de Legislación de las Entidades Fiscalizadoras de América Latina y el Caribe.

Tomo I, II y Suplemento

Lima - Perú

XX CONFERENCIA INTERAMERICANA DE CONTABILIDAD. SANTO DOMINGO.

1993.Trabajos Internacionales y Nacionales.

Tomo I y II. 
R. HERRERA, Juan

1991. El Contador Interamericano y su

Entorno Socio - Económico.

República Dominicana. 